\title{
Kontribusi Produksi Cellular Lightweight Concrete Serat Limbah Pelepah Kelapa Ssawit Terhadap Emisi $\mathrm{CO}_{2}$
}

\author{
Zainuri $^{1}$, Sujianto ${ }^{2}$, Adrianto Ahmad ${ }^{3}$, Feliatra ${ }^{4}$ \\ ${ }^{1}$ Fakultas Teknik Universitas Lancang Kuning Jl.Yos Sudarso Km. 8 Rumbai - Pekanbaru \\ ${ }^{2}$ Fakultas Ilmu Sosial dan Politik Universitas Riau Kampus Bina Widya Km. 12,5 Simpang Baru Pekanbaru. \\ ${ }^{3}$ Dosen Fakultas Teknik Universitas Riau, Kampus Bina Widya KM 12,5 Panam, Pekanbaru, 28293 \\ ${ }^{4}$ Dosen Fakultas Perikanan dan Ilmu Kelautan Universitas Riau, Kampus Bina Widya KM 12,5 Panam, \\ Pekanbaru, 28293
}

\begin{abstract}
The vast palm oil plantations in Riau province which are 2,430,500 hectares (BPS Indonesia, 2017) have great potential as a provider of CPO (Crude Palm Oil) and other byproducts and include waste. The midrib is always lowered along with the decrease in oil palm fruit bunches at harvest. Handling of waste from the midrib is only by stacking it in the field and letting it dry and self-destruct. Oil palm midribs are still a problem today because they can affect the global climate with greenhouse gas emissions. Carbon emissions can still be minimized by utilizing oil palm midribs. This study aims to measure the reduction of $\mathrm{CO}_{2}$ emissions as an added ingredient in the production of fiber CLC. Presentation of research results using descriptive methods. Research conducted in laboratories with an experimental approach is quantitative. The findings of this study are that the use of oil palm fronds as an added ingredient in producing CLC of solar and electric fuel fibers by $1 \mathrm{~m}^{3}$ can reduce $\mathrm{CO}_{2}$ emissions. The conclusion of this study is that $\mathrm{CO}_{2}$ emissions that can be reduced in the manufacture of $1 \mathrm{~m}^{3}$ of fiber CLC using diesel fuel is 111,582 tons/year and when using an electrically driven engine the $\mathrm{CO}_{2}$ emissions that can be reduced are 120.887 tons/year.
\end{abstract}

Key Words: $\mathrm{CO}_{2}$, emissions, midribs, fiber

Perkebunan kelapa sawit yang sangat luas di provinsi Riau yaitu seluas 2.430 .500 hektar (BPS Indonesia, 2017) memiliki potensi yang besar sebagai penyedia CPO (Crude Palm Oil) dan produk sampingan lainnya dan termasuk limbah. Hampir semua bagian tanaman kelapa sawit dapat dimanfaatkan, hanya pelepah dan akar yang belum dimanfaatkan. Pelepah selalu diturunkan bersamaan dengan penurunan tandan buah kelapa sawit pada saat panen. Penanganan limbah pelepah hanya dengan menumpukkan di lahan dan membiarkan kering dan hancur dengan sendirinya.

Limbah pelepah kelapa sawit masih menjadi masalah hingga saat ini sebab pelan tapi pasti ikut mempengaruhi iklim global dengan adanya emisi gas rumah kaca.

Hasil penelitian (Saharjo et al., 2013) memperlihatkan bahwa emisi karbon terbesar tahun 2000 di provinsi Riau berasal dari lahan perkebunan kelapa sawit. Emisi karbon tersebut masih bisa diminimalisir dengan cara memanfaatkan pelepah kelapa sawit.
Proses pembuatan minyak kelapa sawit memberi andil pada peningkatan emisi karbon seperti penelitian yang telah dilakukan oleh Mubekti (2014). Proses produksi industri kelapa sawit yang terdiri dari konversi tutupan lahan, pengelolaan perkebunan, transportasi dan pengolahan di pabrik semuanya memberikan dampak pada peningkatan emisi karbon sebesar 1.641,33 ton per hektar ekivalen $\mathrm{CO}_{2}$.

Pemanfaatan pelepah kelapa sawit pada pengelolaan perkebunan dapat mengurangi andil emisi karbon. Penelitian terhadap pemanfaatan pelepah kelapa sawit ini bertujuan untuk mengukur pengurangan emisi $\mathrm{CO}_{2}$ apabila serat pelepah kelapa sawit digunakan sebagai bahan tambah pada produksi Cellular Lightweight Concrete (CLC) serat. 


\section{BAHAN DAN METODE}

\section{Bahan}

Pelepah kelapa sawit yang diambil seratnya untuk dimanfaatkan berasal dari tanaman kelapa sawit yang berumur 8 tahun lebih. Selain diambil seratnya, untuk pengukuran di laboratorium setiap pelepah yang diuji diambil sampel dengan dimensi $(2 \mathrm{x}$ $2 \times 2$ ) cm masing-masing 3 sampel pada bagian pangkal, 3 sampel pada bagian tengan dan 3 sampel pada bagian ujung..

\section{Metode}

Pemaparan hasil penelitian menggunakan metode deskriptif. Penelitian yang dilakukan di laboratorium dengan pendekatan eksperimental bersifat kuantitatif. Pengujian dan pembuatan sampel dilakukan di laboratorium dan di pabrik CLC untuk menghitung emisi $\mathrm{CO}_{2}$ dari proses produksi CLC serat.

Mesin yang digunakan untuk memproduksi CLC ada 2 jenis yaitu mesin berbahan bakar solar dan mesin yang digerakkan oleh tenaga listrik. Perhitungan emisi $\mathrm{CO}_{2}$ menggunakan mesin berbahan bakar solar sesuai formula IPCC (2006) adalah :

$\mathrm{Emisi}_{\mathrm{GRK}}=\Sigma \mathrm{Ai} \times \mathrm{Efi} \times \mathrm{NCV}$.

Keterangan

Emisi $_{\text {GRK }}$ : Jumlah emisi $\mathrm{CO}_{2}$ (ton)

$\mathrm{Ai} \quad$ : Konsumsi bahan bakar jenis

(ton/tahun)

Efi : Faktor emisi bahan bakar jenis

$(\mathrm{kg} / \mathrm{TJ})$

$\mathrm{NCV}$

massa $(\mathrm{TJ} / \mathrm{kg})$

: Net Calorifis Value per unit

Nilai faktor emisi dari setiap bahan bakar dapat dilihat pada tabel dibawah ini.

Tabel 1. Faktor emisi jenis bahan bakar

\begin{tabular}{lcc}
\hline Jenis bahan bakar & Satuan & $\begin{array}{c}\text { Faktor } \\
\mathbf{C O}_{\mathbf{2}}\end{array}$ \\
\hline Bensin & $\mathrm{Kg} / \mathrm{TJ}$ & 69.300 \\
Solar & $\mathrm{Kg} / \mathrm{TJ}$ & 74.100 \\
Minyak tanah & $\mathrm{Kg} / \mathrm{TJ}$ & 71.900
\end{tabular}

Nilai Net Calorific Value (NCV) pada penelitian ini mengacu pada standar yang ditetapkan oleh IPCC (2006). Dimanan besarnya nilai Net Calorific Value (NCV) jenis bahan bakar solar adalah 43,0 $\quad \mathrm{TJ} / \mathrm{Gg}$ $(0,0000430 \mathrm{TJ} / \mathrm{kg})$.

Perhitungan emisi $\mathrm{CO}_{2}$ yang dihasilkan mesin yang digerakkan oleh tenaga listrik menggunakan rumus Calkins (2009) :

$\mathrm{EC}_{\mathrm{E}}=\mathrm{EE} \times \mathrm{e}_{\mathrm{E}}$

Keterangan :

$\mathrm{EC}_{\mathrm{E}}=$ Embodied emisi $\mathrm{CO}_{2}$ per konsumsi energi

$\mathrm{EE} \quad=$ Embodied Energy $(\mathrm{kWh})$

$\mathrm{e}_{\mathrm{E}} \quad=$ Besarnya emisi $\mathrm{CO}_{2}$ yang dilepaskan dari setiap $\mathrm{kWh}(\mathrm{kg} \mathrm{CO})$

Angka faktor emisi $\mathrm{CO}_{2}$ dari penggunaan listrik

\begin{tabular}{lcc}
\hline \multicolumn{1}{c}{ Tipe Energi } & Satuan & Faktor Emisi \\
\hline Bensin & $\mathrm{kg}-\mathrm{C} / \mathrm{liter}$ & 69.300 \\
Gas & $\mathrm{kg}-\mathrm{C} / \mathrm{kg}$ & 74.100 \\
Listrik & $\mathrm{kg}-\mathrm{C} / \mathrm{kWh}$ & 71.900
\end{tabular}

yang ditetapkan oleh Puslitbangkim (2002) terlihat dalam Tabel 2 berikut ini.

Tabel 2. Faktor emisi bahan bakar

Nilai Embodied Energy (EE) menyatakan sejumlah energi yang digunakan ketika proses produksi berlangsung, sesuai dengan rumusan Calkins (2009) :

$\mathrm{EE}=\mathrm{P} \times \mathrm{H}$

Keterangan :

$\mathrm{EE} \quad=$ Embodied Energy $(\mathrm{kWh})$

$\mathrm{P} \quad=$ Daya listrik (watt, kilowatt)

$\mathrm{H}=$ Waktu proses produksi bahan bangunan

Pemeriksaan kadar karbon yang terkandung dalam pelepah kelapa sawit dilakukan terhadap pelepah yang baru didodos. Setiap pelepah ditimbang dan dibagi menjadi 3 bagian (pangkal, tengah dan ujung) masingmasing bagian diambil 3 sampel berukuran $(2 \mathrm{x}$ $2 \times 2) \mathrm{cm}$ yang kemudian dicincang halus dan dikeringkan menggunakan oven dengan suhu $105^{\circ} \mathrm{C}$ selama 24 jam. Sebelum dan sesudah pengeringan sampel uji ditimbang. Pengukuran yang dilakukan adalah :

1. Berat kering $(\mathrm{kg} /$ pelepah $)=$ Berat basah $\mathrm{x}$ (100 - \% Kadar air)

2. Pendugaan karbon pada biomassa pelepah kelapa sawit diperkirakan menggunakan rumus :

$\mathrm{C}_{\text {biomassa }}(\mathrm{kg} /$ pelepah $)=$ Berat kering (kg/pelepah) x \% C 
3. Pengurangan emisi karbon dioksida $\left(\mathrm{CO}_{2}\right)$ karena pemanfaatan limbah serat pelepah kelapa sawit diperkirakan dengan rumus :

$\mathrm{CO}_{2}=\mathrm{C}_{\text {biomassa }} \times 44 / 12$

\section{HASIL}

\section{Emisi $\mathrm{CO}_{2}$ pada produksi CLC serat}

Serat pelepah kelapa sawit yang digunakan sebagai bahan tambah pada pembuatan batako dan Cellular Lightweight Concrete (CLC) serat dapat meningkatkan kekuatan produk seperti hasil penelitian (Zainuri et al., 2017 dan 2019). Keunggulan pemakaian serat pelepah kelapa sawit dalam produk batako dan CLC dapat dijadikan pertimbangan untuk memproduksi produk tersebut secara masal. Dengan demikian masalah keberadaan limbah pelepah kelapa sawit di perkebunan dapat diminamilisir, terutama masalah peningkatan emisi karbon yang memperparah efek gas rumah kaca. Pelepah yang dibiarkan lapuk dengan sendirinya saja sudah memberi andil dalam meningkatkan emisi karbon. Apabila pelepah kering dapat memicu kebakaran lahan atau hutan yang kerap terjadi setiap tahun sejak tahun 1980.

Pemanfaatan serat pelepah kelapa sawit pada pembuatan CLC serat masih memberikan andil pelepasan $\mathrm{CO}_{2}$ selama proses produksi, namun bila dibandingkan dengan pembiayaran limbah pelepah kelapa sawit di lahan perkebunan, pelepasan emisi karbon ke udara dapat diminimalisir.

Mesin mixer pengaduk bahan-bahan pembuat CLC serat ada yang digerakkan oleh bahan bakar solar ada juga yang digerakkan listrik. Emisi karbon yang dihasilkan kedua mesin tersebut berbeda. Perhitungan emisi karbon dari 2 macam mesin pengaduk tersebut diperhitungkan sesuai dengan kapasitas produksi dalam hal ini dengan satuan $1 \mathrm{~m}^{3}$ produk CLC serat.

\section{Mesin dengan bahan bakar solar}

Untuk memproduksi $1 \mathrm{~m}^{3}$ CLC serat dibutuhkan solar 2,5 liter. Kapasitas produksi harian CLC serat adalah $5 \mathrm{~m}^{3}$, hari kerja per tahun adalah 300 hari, sehingga produksi CLC serat dalam setahun $1.500 \mathrm{~m}^{3}$. Berat jenis solar $0,82-0,86 \mathrm{~kg} / \mathrm{liter}$, dalam perhitungan digunakan BJ solar sebesar $0,82 \mathrm{~kg} /$ liter.

a. Konsumsi solar per tahun
$=1.500 \mathrm{~m}^{3} /$ thn $\quad \mathrm{x} \quad 2,5$ liter $\mathrm{x} \quad 0,82$ $\mathrm{kg} / \mathrm{liter}$

$=3.075 \mathrm{~kg} / \mathrm{thn}=3,075 \mathrm{ton} / \mathrm{thn}$

b. Emisi $\mathrm{CO}_{2}$ yang dilepaskan ke udara per tahun

Emisi $_{\mathrm{GRK}}=\Sigma \mathrm{Ai} \times$ Efi $\mathrm{x} \mathrm{NCV}$

$=3,075$ ton/thn $\mathrm{x} 74.100 \mathrm{~kg} / \mathrm{TJ} \quad \mathrm{x}$

$0,000043 \mathrm{TJ} / \mathrm{kg}$

$=9,798$ ton $/$ tahun

c. Produksi $\mathrm{CO}_{2}$ untuk CLC serat dalam 1 $\mathrm{m}^{3}$

$=9,798 \mathrm{ton} / \mathrm{thn}: 1.500 \mathrm{~m}^{3} / \mathrm{thn}$

$=0,006532 \mathrm{ton} / \mathrm{m}^{3}$

$=6,532 \mathrm{~kg} / \mathrm{m}^{3}$

\section{Mesin dengan tenaga penggerak listrik}

Kapasitas putaran mesin $1 \mathrm{~m}^{3} / 12$ menit dengan tipe mesin menggunakan daya 5 HP (1 $\mathrm{HP}=0,7457 \mathrm{kWh})$. Proses pengadukan $1 \mathrm{~m}^{3}$ CLC serat dengan berbagai kendala dilapangan membutuhkan waktu rata-rata 30 menit. Satu hari kapasitas produksi $5 \mathrm{~m}^{3}$ sehingga total operasi mesin 2,5 jam.

a. Jumlah energi yang digunakan untuk memproduksi CLC serat dalam 1 hari.

$=5 \mathrm{HP} \times(0,5 \mathrm{jam} \times 5$ kali $)$

$=(5 \times 0,7457 \mathrm{kWh}) \times 2,5 \mathrm{jam}$

$=9,32125 \mathrm{kWh} / \mathrm{hari}$

$=9,32125 \mathrm{kWh} /$ hari $\mathrm{x} 300$ hari

$=2.796,375 \mathrm{kWh} /$ tahun

b. Besarnya emisi $\mathrm{CO}_{2}$ yang dikeluarkan oleh pembangkit tenaga listrik.

$=2.796,375 \mathrm{kWh} /$ tahun $\mathrm{x} 0,179 \mathrm{~kg}$ $\mathrm{CO}_{2} / \mathrm{kWh}$

$=500,551125 \mathrm{~kg} \mathrm{CO} /$ tahun

$=0,500551125$ ton $\mathrm{CO}_{2} /$ tahun

$=0,501$ ton $\mathrm{CO}_{2} /$ tahun

c. Emisi $\mathrm{CO}_{2}$ memproduksi CLC serat $1 \mathrm{~m}^{3}$.

$=0,501$ ton $/$ tahun $: 1.500 \mathrm{~m}^{3} /$ tahun

$=0,000334 \mathrm{ton} / \mathrm{m}^{3}$

$=0,334 \mathrm{~kg} / \mathrm{m}^{3}$

\section{Emisi $\mathrm{CO}_{2}$ limbah pelepah kelapa sawit}

Kadar karbon (C) pada limbah pelepah kelapa sawit dapat diukur dengan cara melakukan pengujian di laboratorium. Hasil pengujian tertera dalam Tabel 3 berikut ini. 
Tabel 3. Rata-rata kadar karbon pelepah kelapa sawit

\begin{tabular}{lcccc}
\hline \multicolumn{1}{c}{ Uraian } & $\begin{array}{c}\text { Berat basah } \\
(\mathbf{k g})\end{array}$ & $\begin{array}{c}\text { Berat kering } \\
(\mathbf{k g})\end{array}$ & $\begin{array}{c}\text { Kadar karbon } \\
(\boldsymbol{\%})\end{array}$ & $\begin{array}{c}\text { Berat karbon } \\
(\mathbf{k g})\end{array}$ \\
\hline Pelepah 1 & 5,30 & 1,69 & 51,04 & 0,28 \\
Pelepah 2 & 5,50 & 1,67 & 57,48 & 0,34 \\
Pelepah 3 & 4,20 & 1,49 & 61,00 & 0,30 \\
Pelepah 4 & 5,20 & 1,48 & 76,43 & 0,36 \\
Pelepah 5 & 4,20 & 1,50 & 61,62 & 0,34 \\
Rerata/pelepah & $\mathbf{4 , 8 8}$ & $\mathbf{1 , 5 6}$ & $\mathbf{6 1 , 5 2}$ & $\mathbf{0 , 3 2}$ \\
Rerata/bagian & $\mathbf{1 , 6 3}$ & $\mathbf{0 , 5 2}$ & $\mathbf{2 0 , 5 1}$ & $\mathbf{0 , 1 1}$
\end{tabular}

Berat rata-rata karbon per pelepah adalah $0,32 \mathrm{~kg}$ dari berat basah pelepah $4,88 \mathrm{~kg}$. Potensi $\mathrm{CO}_{2}$ dapat diperhitungkan dengan mengalikan stok karbon (C) dengan koefisien 44/12 atau 3,67 sesuai dengan perhitungan Lukito (2013). Nilai koefisien yang digunakan tersebut dihitung berdasarkan massa atom dari senyawa $\mathrm{CO}_{2}$ dan unsur $\mathrm{C}$. Massa atom $\mathrm{C}$ adalah 12 dan $\mathrm{O}$ adalah 16. Jumlah massa atom $\mathrm{CO}_{2}$ adalah $44((1 \times 12)+(2 \times 16))$. Massa senyawa tersebut dibandingkan dengan massa karbon (C) sehingga angka koefisien yang digunakan adalah 44/12 =3,67.

Perkiraan serapan $\mathrm{CO}_{2}$ dapat dikonversikan dengan stok karbon (C) dari pelepah kelapa sawit. Hasil perhitungan konversi tersebut tertera dalam Tabel 4 berikut ini.

Tabel 4. Faktor emisi bahan bakar

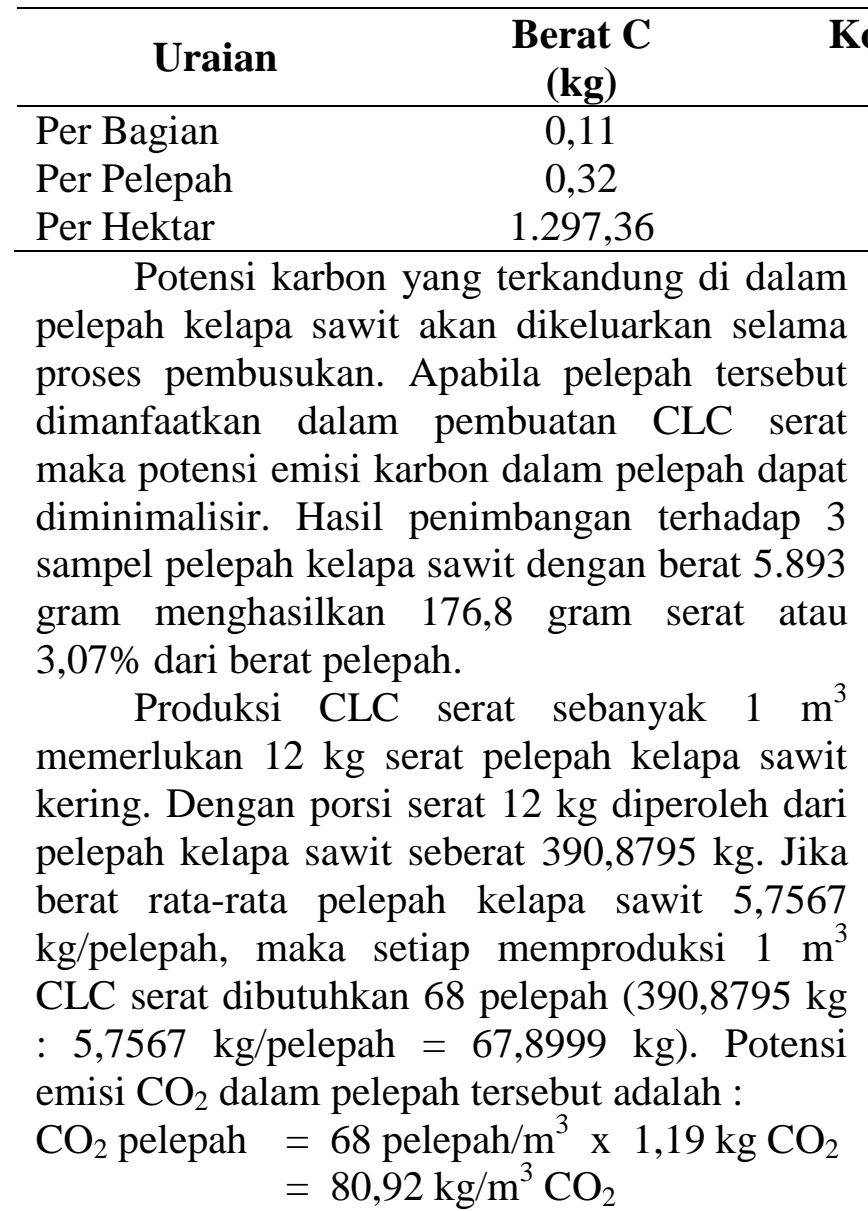

Hasil perhitungan tersebut memperlihatkan bahwa pemanfaatan limbah pelepah kelapa sawit pada pembuatan CLC serat dapat dikurangi sebesar selisih emisi $\mathrm{CO}_{2}$ yang

\begin{tabular}{cc}
$\begin{array}{c}\text { Konversi C ke } \\
\mathbf{C O}_{2}\end{array}$ & $\begin{array}{c}\mathbf{C O}_{2} \\
(\mathbf{k g})\end{array}$ \\
\hline $44 / 12$ & 0,40 \\
$44 / 12$ & 1,19 \\
44,12 & $4.757,00$ \\
\hline
\end{tabular}

dihasilkan mesin pembuat CLC. Emisi $\mathrm{CO}_{2}$ yang dapat diminimalisir adalah:

$$
\text { 1. } \begin{aligned}
\mathrm{CO}_{2} & =80,92 \mathrm{~kg} / \mathrm{m}^{3}-6,532 \mathrm{~kg} / \mathrm{m}^{3} \\
& =74,388 \mathrm{~kg} / \mathrm{m}^{3}
\end{aligned}
$$

2. Emisi karbon yang dikurangi dalam sehari :

$$
\begin{aligned}
& =74,388 \mathrm{~kg} / \mathrm{m}^{3} \mathrm{CO}_{2} \times 5 \mathrm{~m}^{3} / \text { hari } \\
& =371,94 \mathrm{~kg} / \text { hari } \mathrm{CO}_{2}
\end{aligned}
$$

3. Emisi karbon yang dapat dikurangi dalam 1 tahun :

$$
\begin{aligned}
& =371,94 \mathrm{~kg} / \text { hari } \mathrm{CO}_{2} \times 300 \text { hari/tahun } \\
& =111.582 \mathrm{~kg} / \text { tahun } \mathrm{CO}_{2} \\
& =111,582 \mathrm{ton} / \text { tahun } \mathrm{CO}_{2}
\end{aligned}
$$

Emisi karbon dari proses pembuatan CLC serat dari 1 pabrik dapat lebih diminimalisir lagi bila menggunakan mesin listrik. Besaran emisi $\mathrm{CO}_{2}$ yang dapat dikurangi adalah sebagai berikut :

1. Pengurangan emisi $\mathrm{CO}_{2}$ dengan kapasitas produksi $1 \mathrm{~m}^{3}$ :

$=80,92 \mathrm{~kg} / \mathrm{m}^{3}-0,334 \mathrm{~kg} / \mathrm{m}^{3}$

$=80,586 \mathrm{~kg} / \mathrm{m}^{3}$

2. Emisi $\mathrm{CO}_{2}$ yang dapat dikurangi dalam sehari : 


$$
\begin{aligned}
& =80,586 \mathrm{~kg} / \mathrm{m}^{3} \times 5 \mathrm{~m}^{3} / \text { hari } \\
& =402,93 \mathrm{~kg} / \mathrm{hari}
\end{aligned}
$$

3. Emisi $\mathrm{CO}_{2}$ yang dapat dikurangi dalam 1 tahun adalah :

$$
\begin{aligned}
& =402,93 \mathrm{~kg} / \mathrm{hari} \times 300 \text { hari } / \text { tahun } \\
& =120.879 \mathrm{~kg} / \text { tahun } \\
& =120,879 \text { ton/tahun }
\end{aligned}
$$

Emisi $\mathrm{CO}_{2}$ yang dapat dikurangi 120,879 ton/tahun berasal dari 1 pabrik CLC serat dengan kapasitas produksi $5 \mathrm{~m} 3 /$ hari. Dapat dibayangkan emisi $\mathrm{CO} 2$ yang akan dihindari apabila seluruh limbah pelepah dimanfaatkan untuk produksi CLC serat dari beberapa pabrik dengan kapasitas besar. Lingkungan dapat terselamatkan dari emisi karbon yang berasal dari limbah pelepah kelapa sawit dan akan mengurangi dampak gas rumah kaca.

\section{PEMBAHASAN}

Meskipun dalam memproduksi CLC serat memberi andil pada peningkatan emisi karbon sebesar $6,532 \mathrm{~kg} / \mathrm{m}^{3}$ untuk mesin yang berbahan bakar solar dan $0,334 \mathrm{~kg} / \mathrm{m}^{3}$ untuk mesin yang digerakkan dengan listrik, namun andil tersebut sangat kecil bila dibandingkan dengan sektor transportasi seperti hasil penelitian (Sofaniadi et al., 2018) yang meneliti perubahan pola pergerakan sektor transportasi. Sektor transportasi menyumbang 1.110.204 ton $\mathrm{CO}_{2}$ pada tahun 2010 dan terus meningkat, pada tahun 2016 menjadi 7.366.513 ton $\mathrm{CO}_{2}$ /tahun. Dengan perbandingan $0,5-9,8$ ton/tahun : 7.366.513 ton/tahun $\mathrm{CO}_{2}$, maka emisi karbon dari proses pembuatan CLC dapat diabaikan.

Penelitian lain yang dilakukan oleh (Zainuri et al., 2019) apabila serat pelepah kelapa sawit digunakan sebagai bahan tambah dalam pembuatan batako serat, selain dapat meningkatkan kekuatan produk batako serat, pemanfaatan limbah pelepah kelapa sawit pada pembuatan batako dapat mengurangi emisi karbon. Emisi karbon yang dapat dikurangi oleh 1 pabrik batako serat adalah sebesar 231.420,06 ton/tahun.

Selain pelepah kelapa sawit, batang kelapa sawit juga mengandung karbon. (Siswoko et al., 2017) memperkirakan emisi $\mathrm{CO}_{2}$ dari batang sawit. berat kering batang sawit dengan rata-rata $394,11 \mathrm{~kg} /$ pohon dan setiap hektar pohon sawit memiliki berat kering 50,45 ton. Perhitungan kandungan karbon biomassa bagian batang diperoleh nilai ratarata 223,66 kg C/pohon sehingga tiap hektar memiliki potensi 26,63 ton $\mathrm{C}$ yang berekivalen dengan kadar $\mathrm{CO}_{2}$ sebanyak 104,97 ton $\mathrm{CO}_{2}$ /ha.

Emisi karbon tidak hanya dihasilkan dari limbah perkebunan saja. Aktivitas rumah tangga pun menyumbangkan emisi $\mathrm{CO}_{2}$ ke udara dalam jumlah yang besar. Penelitian (Wirosoedarmo et al., 2017) menghitung total emisi $\mathrm{CO}_{2}$ yang dihasilkan dari aktivitas di Perumahan Sawojajar yaitu sebesar 13.540.001,95 kg/tahun. Kemampuan penyerapan $\mathrm{CO}_{2}$ dari ruang terbuka hijau di lokasi tersebut diperhitungkan sebesar 5.760.532,25 kg/tahun, berarti emisi $\mathrm{CO}_{2}$ yang belum terserap sebesar 7.779.469,7 $\mathrm{kg} /$ tahun sehingga kelebihan emisi $\mathrm{CO}_{2}$ tersebut memberi andil pada peningkatan gas rumah kaca. Jika ruang terbuka hijau tidak segera ditambah maka emisi $\mathrm{CO}_{2}$ yang dihasilkan oleh aktivitas perumahan tersebut akan berdampak buruk terhadap lingkungan.

Khusus emisi $\mathrm{CO}_{2}$ yang dihasilkan oleh limbah pelepah kelapa sawit diperkebunan, dengan dimanfaatkannya limbah pelepah kelapa sawit tersebut maka emisi $\mathrm{CO}_{2}$ dapat diminimalisir. Temuan dari penelitian ini adalah bahwa pemanfaatan serat pelepah kelapa sawit pada pembuatan CLC serat dari 1 pabrik dengan kapasitas produksi $5 \mathrm{~m}^{3} /$ hari menggunakan mesin berbahan bakar solar atau listrik dapat mengurangi emisi $\mathrm{CO}_{2}$ dari limbah pelepah kelapa sawit sebesar 111,582 ton/tahun dan 120,879 ton/tahun.

\section{SIMPULAN}

Kesimpulan penelitian ini adalah emisi $\mathrm{CO}_{2}$ yang dapat dikurangi dengan memanfaatkan limbah pelepah kelapa sawit pada pembuatan CLC serat sebanyak $1 \mathrm{~m}^{3}$ menggunakan bahan bakar solar adalah $74,388 \mathrm{~kg} / \mathrm{m}^{3} \mathrm{CO}_{2}(111,582$ ton/tahun $\mathrm{CO}_{2}$ ). Apabila dalam memproduksi CLC serat sebanyak $1 \mathrm{~m}^{3}$ dengan menggunakan mesin yang digerakkan dengan listrik, maka potensi emisi $\mathrm{CO}_{2}$ yang dapat dikurangi adalah $80,586 \mathrm{~kg} / \mathrm{m}^{3} \mathrm{CO}_{2}\left(120,879\right.$ ton/tahun $\left.\mathrm{CO}_{2}\right)$. 


\section{UCAPAN TERIMA KASIH}

Terima kasih penulis ucapkan kepada semua pihak yang telah memberikan bantuan dan fasilitas dalam menyelesaikan penelitian ini.

\section{DAFTAR PUSTAKA}

Badan Pusat Statistik Provinsi Riau. (2016). Provinsi Riau Dalam Angka 2016. Pekanbaru.

Calkins, M. (2009). Materials for Sustainable Sites. John Wiley \& Sons. Inc. Canada.

IPCC. (2006). Pedoman IPCC Untuk Inventarisasi Nasional Gas Rumah Kaca; Nasional Greenhouse Gas Inventories Program. Jepang

Lukito, M. dan Rohmatiah, A. (2013). Estimasi Biomassa dan Karbon Tanaman Jati Umur 5 Tahun (Kasus Kawasan Hutan Tanaman Jati Unggul Nusantara (JUN) Desa Krowe, Kecamatan Lembeyen Kabupaten Magetan). Jurnal Agri-tek, 14 (1), 1-23.

Mubekti. (2014). Carbon Estimation in Palm Oil Industry. Jurnal Teknologi Lingkungan, 15 (1), 35-42.

Puslitbangkim (Pusat Penelitian dan Pengembangan Pemukiman) Departemen Pekerjaan Umum. (2002). Keputusan Menteri Pemukiman dan Prasarana Wilayah Republik Indonesia No. 403/KPTS/M/2002 Tentang Pedoman Teknis Pembangunan Rumah Sederhana Sehat (Rs. Sehat). Bandung.

Saharjo, B.H., Putra, E.I. and Putra, R.M. (2013). Pendugaan Emisi Karbon $\left(\mathrm{CO}_{2}\right)$ Akibat Kebakaran Hutan dan Lahan pada Berbagai Tipe Penutupan Lahan di Propinsi Riau Tahun 2000-2009. Jurnal Silvikultur Tropika, 4 (3), 130-135.

Siswoko, E., Mulyadi, A., Thamrin dan Bahruddin. (2017). Estimating Carbon Stock of Oil Palm Trunks Waste as Replanting Management in Riau Province. Jurnal Ilmu Lingkungan, 11 (2), 154-163.

Sofaniadi, S., Purwanto, P. and Riyanto, B. (2018). Evaluation of Greenhouse Gas Emission from Transportation Sector in Semarang, Indonesia. "Pollution Research" EM International, 37 (3), 658-662.

Wirosoedarmo, R., Haji, A.T.S. and Gustinasari, K. (2017). Effect of Conversion of
Agriculture Land on Air Pollution Emission of $\mathrm{CO}_{2}$ (The Case Study in The Settlement Sawojajar, Malang, East Java, Indonesia. EM International "Pollution Research", 36 (4), 729-736.

Zainuri, Yanti, G. and Megasari, S.W. (2017). Batako Quality Optimization with Addition of Palm Oil Stem Fiber from Kampar District and Dumai City. International Conference on Environment and Technology (IC-Tech) 2017. IOP Conference Series: Earth and Environmental Science, 97 (1), 1-6. 26-27 July 2017, Pekanbaru, Indonesia. Published under licence by IOP Publishing Ltd. doi:10.1088/1755-1315/97/1/012018.

Zainuri, Zargustin, D., Yanti, G. and Megasari, S.W. (2019). Reduction of $\mathrm{CO}_{2}$ Emissions from Utilization of Palm Oil Midrib Waste in Fiber Brick Production. Jurnal Teknologi Lingkungan, 20 (1), 37-44.

Zainuri, Sujianto, Ahmad, A., and Feliatra (2019). Comparison of Cellular Lightweight Concrete With Addition of Palm Oil Midribs. International Journal of Civil Engineering and Technology (IJCIET), 10 (04), 1211-1218. 